Originally published as:

Hedderich, R., Müller, R., Greulich, Y., Bannert, N., Holland, G., Kaiser, P., Reissbrodt, R. Mechanical damage to Gram-negative bacteria by surface plating with the Drigalski-spatula technique (2011) International Journal of Food Microbiology, 146 (1), pp. 105-107.

DOI: 10.1016/j.ijfoodmicro.2011.02.005

This is an author manuscript.

The definitive version is available at: http://www.sciencedirect.com/ 


\title{
Mechanical damage to Gram-negative bacteria by surface plating with the Drigalski-spatula technique
}

\author{
Reiner Hedderich ${ }^{a}$, Rolf Müller ${ }^{a}$, Yasmin Greulich ${ }^{a}$, Norbert Bannert ${ }^{b}$, Gudrun Holland ${ }^{b}$, Petra Kaiser ${ }^{b}$, \\ Rolf Reissbrodt ${ }^{\mathrm{C}}$ \\ a heipha Dr. Müller GmbH, Eppelheim, Germany \\ ${ }^{b}$ Robert Koch Institut, Berlin, Germany \\ ${ }^{\mathrm{c}}$ Robert Koch Institut, Wernigerode Branch, Wernigerode, Germany
}

\begin{abstract}
Colony counting by spreading bacterial suspensions on plating media by various techniques is of general concern. Comparative studies between hand plating (Drigalski-spatula technique) for different time intervals and spiral plating resulted in significant differences in colony counts. Lower counts of Gram-negative bacteria were obtained by using hand plating for more than $10 \mathrm{~s}$, compared with short time hand plating (5 s) or spiral plating. Colony counting of Gram-positive bacteria showed no differences between both techniques. Further characterisation of Escherichia coli cells spread with the Drigalski-spatula technique by electron microscopy revealed a large number of damaged cells compared to control samples. The data clearly shows that the mechanical forces during hand plating are sufficient to damage $\mathrm{E}$. coli cells.
\end{abstract}

\section{Research Highlights}

Different surface plating techniques result in significant differences in the recovery of Gramnegative bacteria.

- Mechanical forces during hand plating are sufficient to damage cells of Gram-negative bacteria.

- Efflux of cell content is observed by EM after mechanical damage of $E$. coli cells.

\section{Introduction}

Common methods for the estimation of viable microorganisms involve the pour plate or surface plate techniques ( [European Pharmacopoeia 6.0, 2008] and [ISO/TS 11133-2, 2003]). For surface plating cells can be either dispensed on the agar surface with a glass or plastic-spatula (Drigalski-spatula) or alternatively with a spiral plater. The spiral plater is a dispenser that deposits a liquid in a spiral pattern on the surface of a rotating agar plate (Gilchrist et al., 1973). Previous comparative studies of viable counting methods reveal comparable results for the spiral plating method with other techniques ( [Donnelly et al., 1976] and [Greenwood et al., 1984]). Preliminary data from our labs has revealed significant differences in the recovery of Gram-negative bacteria when bacterial suspensions were spread by hand plating as compared to spiral plating. This prompted us to investigate this observation in more detail.

\section{Materials and methods}

\subsection{Bacterial strains, culture conditions and strain-characterization}

Escherichia coli ATCC 8739, Pseudomonas aeruginosa ATCC 9027, Bacillus subtilis ATCC 6633 and Staphylococcus aureus ATCC 6538 were freshly cultivated on nutrient agar, ready-to-use plates (lot CHB 844070, Oxoid, Basingstoke, UK) or on brain heart infusion broth (heipha Dr. Müller $\mathrm{GmbH}$, Eppelheim, Germany) at $36+/-1{ }^{\circ} \mathrm{C}$ overnight. Suspensions of ca. $10^{10} \mathrm{CFU} \mathrm{ml}{ }^{-1}$ in saline were streaked onto Mueller Hinton agar with $5 \%$ sheep blood (Oxoid, ready-to-use plates) and onto BileChrysoidin-Glycerol-Agar (SIFIN, Berlin, Germany). Pure colonies grew typically on the plating media. 


\subsection{Plating experiments}

Diluted suspensions ( $40 \mu \mathrm{l}$ ) of E. coli ATCC 8739, P. aeruginosa ATCC 9027, B. subtilis ATCC 6633 and of S. aureus ATCC 6538 containing 10-100 CFU were plated on tryptic soy agar (ready to use plates of suppliers A, B and C) by hand plating (Drigalski-spatula) for 5,10 and $20 \mathrm{~s}$ or by spiral plating using the uniform mode (Autoplate 4000, Spiral Biotech, Norwood, USA). Plates were subsequently incubated at $36+/-1^{\circ} \mathrm{C}$ overnight. The grown colonies were counted.

\subsection{Spreading cells on agar plates and cell preparation for electronmicroscopy}

$0.1 \mathrm{ml}$ of the suspensions (ca. $10^{10} \mathrm{CFU} \mathrm{ml^{-1 }}$ ) described above were separately plated on nutrient agar (see above) by hand plating (Drigalski-spatula) until dry (ca. $15 \mathrm{~s}$ ). $0.4 \mathrm{ml}$ of saline solution was added immediately and the cells were gently resuspended using a Drigalski-spatula. To obtain sufficient cells, suspensions of at least four of such experiments were pooled and cells were pelleted at $2500 \times g$ for $10 \mathrm{~min}$. In parallel, $0.1 \mathrm{ml}$ of the same bacterial suspensions was pipetted on nutrient agar plates without the spatula technique, washed away with $0.4 \mathrm{ml}$ saline solution and pelleted as described above.

Cell pellets were resuspended in $0.2 \mathrm{ml}$ fixation solution consisting of $20 \mathrm{~g}$ paraformaldehyde in $0.05 \mathrm{M}$ HEPES, $\mathrm{pH}$ 7.2. Before use, the fixation solution was heated at $60^{\circ} \mathrm{C}$ for $30 \mathrm{~min}$ for activation and subsequently diluted 1:10.

As a control the original cell suspensions (ca. $10^{10} \mathrm{cfu} \mathrm{ml}^{-1}$ ) were fixed as described above.

\subsection{Electronmicroscopy}

For negative staining EM the fixed bacterial pellets were centrifuged again and adsorbed on Pioloform-F coated, carbon stabilised and glow-discharged copper grids. The adherent bacteria were washed three times with distilled water. After negative staining with $0.5 \%$ uranyl acetate $(\mathrm{pH} 4.0-4.5)$ the samples were analyzed using an electronmicroscope TEM 902 (Zeiss, Oberkochen, Germany) at $80 \mathrm{kV}$ and their images digitised using a slow scan CCD-camera (Proscan, Scheuring, Germany).

\subsection{Statistical analysis}

Results shown in Table 1 and Table 2 are expressed as mean values with standard deviations. Pairwise comparisons were performed with Student's $t$-test (SPSS 13.0, Chicago, USA). Multiple group comparisons were performed with one-way ANOVA, followed by Dunnett-T3 test (SPSS 13.0, Chicago, USA) to compare multiple experimental groups pairwise. Significant levels were set at $P$ values $<0.05$.

\section{Results and discussion}

Table 1 shows the colony counts of E. coli ATCC 8739 obtained after hand plating (Drigalski-spatula technique) with different time intervals compared to spiral plating. Using the hand plating technique, an increasing plating time resulted in a decrease in plate counts. Maximal counts were obtained by hand plating for $5 \mathrm{~s}$ and by spiral plating. Hand plating for $20 \mathrm{~s}$ resulted in strongly reduced plate counts (Table 1). This was observed on ready to use plates from different suppliers (Table 2). Comparable data were obtained for $P$. aeruginosa ATCC 9027 (Table 1). In contrast, for the Gram-positive bacteria B. subtilis ATCC 6633 and S. aureus ATCC 6538, colony counts were in the same range regardless of the plating technique (Table1). For $S$. aureus hand plating for $10 \mathrm{~s}$ and $20 \mathrm{~s}$ even resulted in a slight increase in colony counts. This is probably due to a disaggregation of $S$. aureus cell aggregates from the mechanical treatment.

It was hypothesized that Gram-negative bacteria are mechanically damaged by squeezing during hand plating. To demonstrate such squeezing, E. coli and S. aureus were dispensed on nutrient agar 
with a Drigalski-spatula (for $15 \mathrm{~s}$ ) or simply pipetted on the plates without further treatment. The cells were recovered from the plates by washing with saline and subsequently characterized by electronmicroscopy. Fig. 1b provides unequivocal evidence for the efflux of $E$. coli cell content when cells were dispensed with a Drigalski-spatula. No efflux of cell content was observed in the E. coli control samples (Fig. 1a and c) or with S. aureus (Fig. 2).

Obviously, E. coli ATCC 8739 cells and $P$. aeruginosa ATCC 9027 cells were squeezed by using the Drigalski-spatula technique. Hence, normal hand-pressure is sufficient to disrupt the cell wall of Gramnegative bacteria. The cell wall of S. aureus ATCC 6538 and of $B$. subtilis ATCC 6633 is stable enough to withstand this pressure. Hand plating as described here is a common method for colony counting by ISO-standards, EP and USP, as well as national standards ( [European Pharmacopoeia $6.0,2008]$ and [ISO/TS 11133-2, 2003]). The data provided here shows that the plating method can largely influence recovery rates. This issue clearly requires more attention and discussion by the committees.

\section{References}

Donnelly, C.B., Gilchrist, J.E., Peeler, J.T., Campbell, J.E., 1976. Spiral plate count method for the examination of raw and pasteurized milk. Applied and Environmental Microbiology 32, 21-27.

European Pharmacopoeia 6.0, 2008. Microbiological examination of non-sterile products. Total viable aerobic count. 2.6.12, pp. 166-173.

Gilchrist, J.E., Campbell, J.E., Donnelly, C.B., Peeler, J.T., Delaney, J.M., 1973. Spiral plate method for bacterial determination. Applied Microbiology 25, 244-252.

Greenwood, M.H., Coetzee, E.F.C., Ford, B.M., Gillt, P., Hooper, W.L., Matthews, S.C.W., Patrick, S., Pether, J.V.S., Scott, R.J.D., 1984. The microbiology of selected retail food products with an evaluation of viable counting methods. The Journal of Hygiene 92, 67-77.

ISO/TS 11133-2, 2003. Microbiology of food and animal feeding stuffs - Guidelines on preparation and production of culture media - Part 2: Practical guidelines on performance testing of culture media. 


\section{Tables and Figures}

Table 1. Comparison of the recovery (CFU) of selected strains after hand plating and spiral plating on tryptic soy agar plates (mean values \pm standard deviations of ten plates).

\section{Recovery (CFU)}

\section{Hand plating (plating time) Spiral plating}

$\begin{array}{lclll}\text { E. coli ATCC } 8739 & 97 \pm 11 & 40 \pm 13^{\mathrm{a}} & 22 \pm 4^{\mathrm{a}} & 109 \pm 9 \\ \text { P. aeruginosa ATCC } 902766 \pm 14 & 30 \pm 9^{\mathrm{a}} & 11 \pm 5^{\mathrm{a}} & 59 \pm 9 \\ \text { B. subtilis ATCC 6633 } & 34 \pm 8 & 28 \pm 8 & 29 \pm 9 & 30 \pm 5 \\ \text { S. aureus ATCC } 6538 & 74 \pm 6 & 77 \pm 8 & 85 \pm 7 & 88 \pm 13\end{array}$

${ }^{\text {a }}$ Recovery after handplating is significantly different $(P<0.05)$ as compared to spiral plating. Comparable results were obtained in three independent experiments using different batches of tryptic soy agar.

Table 2. Recovery rates of E. coli ATCC 8739 after hand plating with different time intervals on ready to use tryptic soy agar plates from different suppliers (mean values \pm standard deviations of four plates).

\begin{tabular}{ll} 
Supplier $^{\mathrm{a}}$ & \multicolumn{2}{l}{ Recovery rates (\%) of E. coli ATCC 8739} \\
\cline { 2 - 3 } & \multicolumn{2}{c}{$\mathbf{5}$ s hand plating } & \multicolumn{1}{c}{$\mathbf{2 0}$ s hand plating } \\
Supplier A $93 \pm 15$ & $6 \pm 1^{\mathrm{b}}$ \\
Supplier B $72 \pm 9$ & $13 \pm 6^{\mathrm{b}}$ \\
Supplier C $110 \pm 12$ & $6 \pm 2^{\mathrm{b}}$
\end{tabular}

${ }^{a}$ Ready to use tryptic soy agar plates from different suppliers (A, B and C), packed in cellophane and stored at $8{ }^{\circ} \mathrm{C}$, were tested at the end of shelf life. Columbia blood agar served as a reference medium using $5 \mathrm{~s}$ hand plating to spread the bacteria (= $100 \%$ value).

${ }^{\mathrm{b}}$ Recovery rates after $20 \mathrm{~s}$ handplating are significantly different $(P<0.05)$ from recovery rates after 5 s handplating. 
Figure 1. Electronmicroscopic demonstration of the mechanical damage to E. coli ATCC 8739 cells. a) original sample, b) after hand plating, efflux of most cell content, formation of ghosts, c) control sample spotted on agar plates without treatment with a Drigalski-spatula, no efflux of cell content.

a)

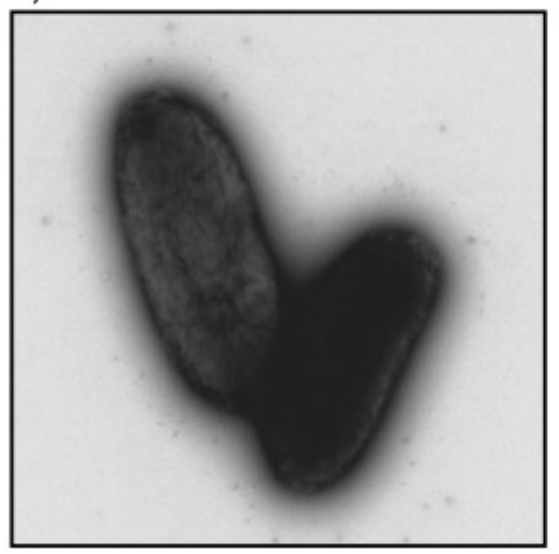

b)

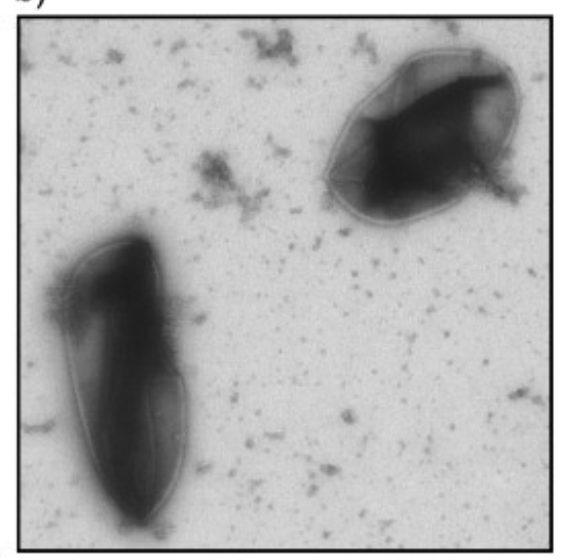

c)

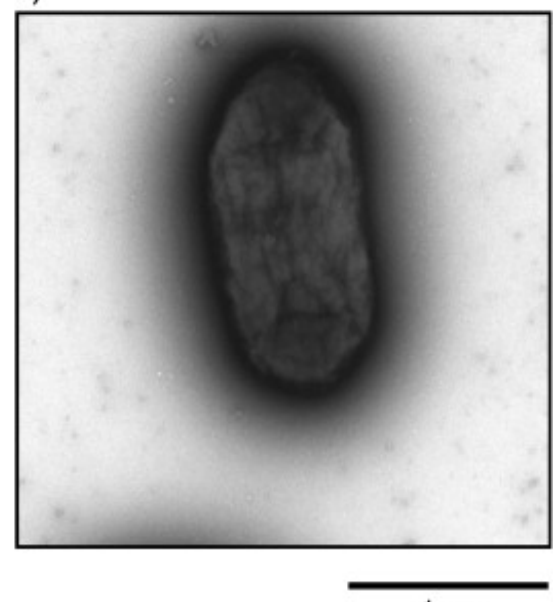

$1 \mu \mathrm{m}$

Figure 2. Demonstration of the mechanical stability of S. aureus ATCC 6538 cells by electronmicroscopy. a) original sample, b) after hand plating, no efflux of cell content, c) control sample spotted on agar plates without treatment with a Drigalski-spatula, no efflux of cell content.

a)

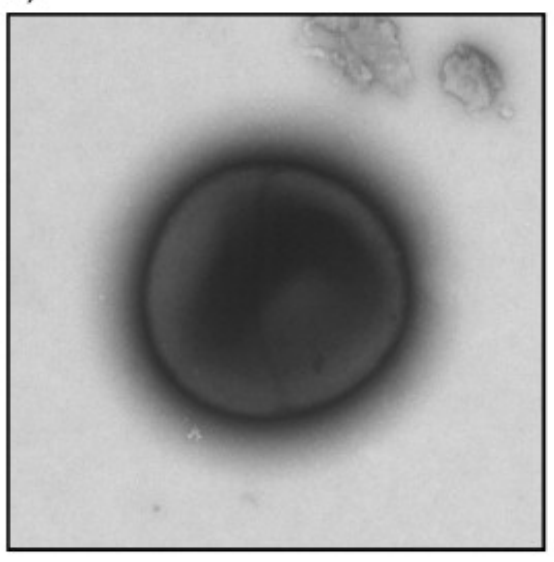

b)

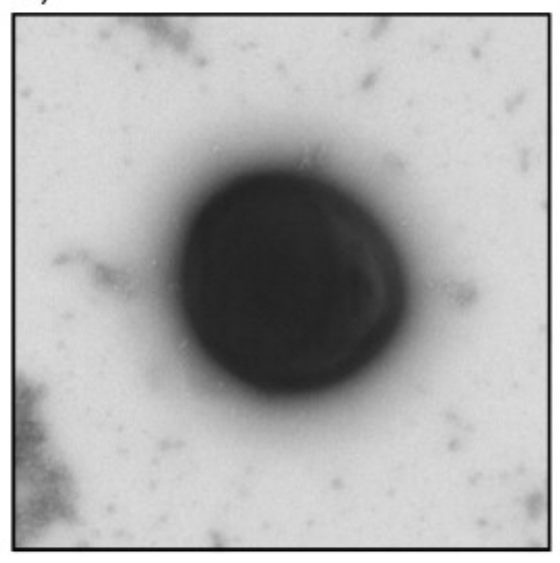

c)

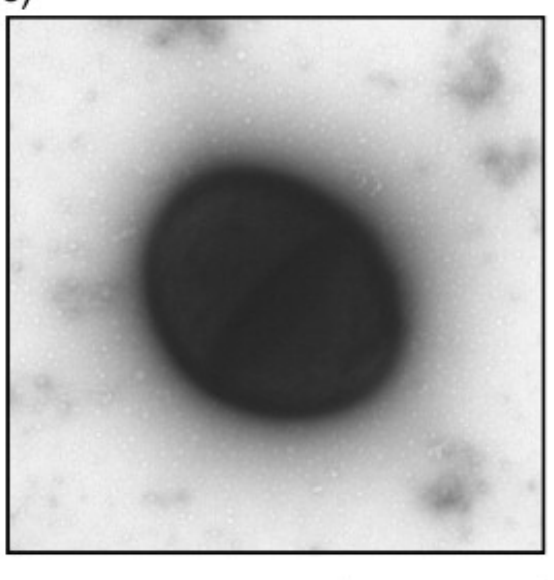

